When we consider the salient physical signs it is clear that as far as the eye is concerned the condition is a partial iridoplegia. Since the name tonic pupil gives no descriptive clue to the anatomical position of the lesion, the term "ciliary ganglion iridoplegia" is suggested as being a more correct name.

\title{
Summary
}

1. The physical signs of the syndrome are given.

2. The anatomy of the ocular reflexes concerned is described with diagrams.

3. A lesion capable of producing the physical signs in the eye is postulated by deduction.

4. Physical signs which clearly differentiate the tonic pupil syndrome from tabes are pointed out.

5. The anatomical situation of the lesion responsible for the loss of knee and ankle jerks in the tonic pupil syndrome is postulated.

6. A descriptive name is suggested.

\section{THE SIGNIFICANCE OF A LESION OF THE OPTIC NERVE}

\author{
BY \\ G. JOLY Dixon \\ LONDON
}

THOUGH the optic nerve can be visually inspected at the beginning of its course, and its functions measured accurately both quantitatively and qualitatively, it is surprising how often the diagnosis of lesions in this structure remains doubtful. True, such lesions are often only part of a pathological process occurring elsewhere in the body, and the symptoms that have led to the discovery of the lesion in the optic nerve are really related to some much more generalised process; and, further, two entirely different processes may, for a time at least, produce the same syndrome in the optic nerve.

For example, an appearance at first indistinguishable from the papilloedema that so often accompannies cerebral tumour was seen in the following two cases of hypertension :-

Case 1.-A man aged 48 years attended the Royal Westminster Ophthalmic Hospital for the first time on February 13, 1939, under the care of Mr. Hine and Dr. Hickling, because a few days 
before he had noticed mistiness of the left eye and found this eyeball both tender on pressure and painful to move. On examination there was generalised reduction of visual acuity in the left eye (vision 6/24), but no definite field defect; vision of the right eye was normal $(6 / 5)$. On ophthalmoscopy he had the typical appearance of early bilateral papilloedema (swelling of both discs and some exudates and haemorrhages strictly confined to the disc area), the rest of the fundi was normal, though it was noted that his retinal arteries had the appearances one associates with hypertension. His blood prèssurè was $205 / 78$, he had no albuminuria, and a barrel shaped chest precluded accurate estimation of the size of his heart. As he was obviously very nervous, the raised blood pressure was discounted, and he was admitted on March 10, 1939, to Charing Cross Hospital with the provisional diagnosis of cerebral tumour. Lumbar puncture and manometric observation showed the cerebro-spinal fluid to be at a pressure of $300 \mathrm{~mm}$. (the normal variation being 80 to $150 \mathrm{~mm}$.); an examination of the fluid showed no excess of globulin, protein 0.040 per cent. (normal), chlorides 0.716 per cent., one cell per cubic centimetre (normal one to four cells per cubic centimetre), and Wassermann reaction to be negative. He spent four weeks in hospital, and during this time developed an albuminuria. His blood urea was found to be 184 milligrammes per 100 cubic centimetres, frequent blood pressure readings gave a representative value of $225 / 145$. In addition later ophthalmoscopy revealed a substantial alteration of the original picture; there was no further swelling of the optic papillae, but fresh exudates appeared throughout both fundi, chiefly in the region of the maculae; so that ten weeks after he was first seen he presented the typical picture of albuminuric retinitis with star figures around both maculae.

Case 2.-A male patient aged 54 years, admitted January 8, 1940, to the National Hospital, Queen Square, under the care of Dr. Walshe. During the previous eighteen months he had suffered from frequent and severe headaches often accompanied by vomiting. For two months there had been a profound change in character; he appeared to have lost the power of performing the simplest mechanical tasks. On the whole he appeared drowsy, but although he spent the greater portion of the day sleeping, he suffered from frequently recurring periods of restlessness and motor excitability, which occurred at least as often during the night as during the day.

On admission to hospital these observations were confirmed, and in addition it was noted that though he was correctly orientated in time and space, he was euphoric and so slow in the uptake as to be almost apraxic. As he lay in bed he spent a large portion of the day rubbing his nose with either hand. 
His vision was normal (right $6 / 6$, left $6 / 9$ ), and there were no field defects. On ophthalmoscopy he was thought to have bilateral papilloedema; the right disc was blurred and its surface covered by a few exudates and striate haemorrhages; there were a few new vessels on its surface, and there were four dioptres of swelling. The appearance of the left disc was the same, though in this case the swelling was estimated as three dioptres. Apart from a few opalescent spots around the maculae, there were no other changes in the fundi. No other abnormalities of his central nervous system were found; his heart was enlarged, 'and there was accentuation of the second aortic sound, the blood pressure was 220/170, and he had albumen and red blood cells in his urine.

On lumbar puncture with manometric readings, his cerebrospinal fluid was found to be at a pressure of $220 \mathrm{~mm}$., to contain one cell per cubic millimetre and 0.100 grammes per cent. of protein and some increase of globulin. An estimation of his blood urea gave a value of 51 milligrammes per 100 cubic centimetres.

In the course of three weeks he developed further exudates and haemorrhages in the fundi remote from the disc, and in addition suffered from three attacks of deep coma, during the last of which he developed hyperpyrexia and died. A lumbar puncture performed.twelve hours before death revealed a manometric pressure of over 300 millimetres of water.

There was considerable discussion as to whether the changes in the fundus should be regarded as an atypical albuminuric retinitis occurring in a patient with an almost normal blood urea, or as papilloedema due to a frontal tumour in a patient who also suffered from hypertension.

At autopsy there was no cerebral tumour, but the heart was greatly enlarged and had all the changes one usually associates with hypertension.

Cases of hypertension with similar findings in the retina have been previously described by Traquair (1930), Murphy and Grill (1930), and Draganesco and Lazaresco (1939).

Paton and Holmes (1910) have shown that the swelling of the optic disc described as papilloedema in cases of cerebral tumour is due to oedema and venous congestion of the distal vascular portion of the optic nerve, which in turn is due to the raised intracranial pressure compressing the central vein of the retina as it traverses the subdural space of the optic nerve; and that papilloedema in chronic meningitis is also due to the raised cerebrospinal fluid pressure. It is not then surprising that an identical appearance will be seen in those cases of hypertension that show raised cerebro-spinal pressure as an early sign.

Papilloedema is also usually found, Jefferson (1940) in cases of tumour of the optic nerve, and in these the probable mechanism 
is venous obstruction occurring in the distal vascular portion of the optic nerve.

Paton (1914) pointed out that a transitory swelling of the optic disc which is indistinguishable on inspection from papilloedema, occurs occasionally in disseminated sclerosis; but these cases differ from papilloedema of cerebral tumour in that there is invariably a severe loss of vision, usually in the form of a central scotoma. The term papillitis has been suggested to describe these cases.

Thus, since the one lesion may be produced by several distinct diseases, it may be impossible to determine its cause in patients who otherwise present no evidence of disease. Some of these will be due to an indisputable cause such as a tumour of the nerve or its involvement in a fracture of the skull, but when such evidence is lacking, the diagnosis and prognosis are subject to considerable discussion. The most widely held view is that of Buzzard (1890), Uhthoff (1890), Adie (1930), Benedict (1933) and Lillie (1934), who believe that the vast majority of these cases will sooner or later develop disseminated sclerosis. According to Walshe (1940), the interval that may be expected to elapse before further symptoms will develop varies from a few months up to fifteen years. Adie (1930) gives one instance where this interval was forty-seven years. Others (Gunn 1896, Onodi 1908, Loeb 1909, White 1919, 1924, 1928, Crane 1927 and Coffin 1928) stress the importance of disease in the paranasal sinuses, or focal sepsis, in the aetiology of these cases, and report numerous cures resulting from operations designed to eradicate these conditions. However, as equally good results are obtained in cases that are not submitted to operation, these procedures are becoming less popular, and it would appear that the theory is also passing into disrepute.

It is indisputable that patients presenting with an optic nerve lesion, especially when that lesion is retrobulbar neuritis, are very often early cases of disseminated sclerosis; and, further, a proportion of these patients at the time they are first seen have no further evidence of this disease. On the other hand, cases like the following raise the possibility that there are other conditions that may produce lesions in the optic nerve.

Case 3.-In July 1928 a boy aged 15 years developed severe pain behind the right eye, followed by progressive loss of vision in both eyes. After five weeks he was admitted to the National Hospital, Queen Square, under the care of the late Dr. Adie; at this time the sight in his right eye was reduced to perception of hand movements, and in the left to $6 / 36$. Both visual fields showed irregular concentric contraction; on the right the blind area occupied the whole of the lower portion of the field and spread up over the fixation point to the lower portion of the upper segments. There were no obvious changes in the fundi; the pupil reflexes to light were 
present though sluggish, with hippus on the right. A complete examination of his central nervous system, a lumbar puncture and X-ray. of the skull showed no further abnormality. During an eight weeks stay in hospital his sight improved substantially, and on discharge his right vision was $3 / 36$ and left vision $6 / 12$.

He remained well till October 1936, when he developed pain in the left eye and suddenly lost its sight. At this time the vision in the right eye was $6 / 6$, but in the left eye it was reduced to the perception of hand movements; the right disc was pale and atrophic, but the left was pink and swollen. The sight in the left eye improved gradually, but meanwhile the right eye became affected, though it in turn also improved (examination one week after recurrence showed right vision $6 / 36$, left vision $6 / 12$, and three weeks later right vision $6 / 12$, left vision $6 / 9$ ).

A third recurrence occurred in December 1939-the left eye became painful, and during the subsequent two days the sight in that eye failed. On examination the right vision was $6 / 5$ and the left vision $2 / 60$, the left field showed a large inferior nasal defect and a central scotoma, the right field was full, both discs were found to be very pale and atrophic. He made a complete recovery, and four weeks later the right vision was $6 / 5$ and the left vision $6 / 9$.

At the time of the two recurrences he was submitted to complete examination of the central nervous system without the discovery of any further abnormality.

Traquair (1930) describes five cases similar to the above, one of which he had under observation for seventeen years, and makes the suggestion that these may be examples of a condition analogous to disseminated sclerosis that is confined to the optic nerve. He offers, however, no pathological evidence in favour of this view.

\section{Survey of Cases of Optic Nerve Lesion}

It was decided that it would be interesting to review carefully a series of cases of optic nerve lesion and determine in what proportion a clinical diagnosis could be made with any certainty, and then observe both diagnosed and undiagnosed cases for a number of years and see how far in the first case the prognosis was fulfilled and in what proportion of the others the diagnosis was revealed.

The series chosen for this purpose consisted of all cases referred by the Ophthalmic Surgeons on the staff of the Medical Department of the Royal Westminster Ophthalmic Hospital in 1931. There were twenty-seven such cases; all of them were sufficiently well when first seen for the condition to be regarded by themselves or by their doctors as primarily ophthalmological, and also sufficiently well to attend the Hospital several times as out-patients. 
In twenty-four cases it was possible to submit the patient to a complete clinical (including careful neurological) examination, take a blood Wassermann and examine the nasal sinuses radiographically. Where any of these examinations gave reasonable indication, the patient was admitted to Charing Cross Hospital for lumbar puncture, or submitted to a complete intra-nasal examination.

Of these twenty-four patients, six were found to have indisputable evidence of disseminated sclerosis; five were found to have tabes dorsalis, two had cerebral tumour, and one optic nerve lesion was due to trauma.

None of the better known causes of optic nerve lesion was found in the remaining ten cases in spite of very complete and extensive examination in 1931. In two (cases S2 and S3), after ten years observation it was decided that the optic nerve lesion was due to arteriolar sclerosis. One patient, a girl aged 19 years (case S4), developed other signs of disseminated sclerosis two years later, and in a child aged 9 years (case S1), papilloedema was found, associated with past irido-cyclitis and chorea. It has been possible to re-examine carefully five of the remaining seven patients, and in none of these has any further evidence of the cause of the optic nerve lesion transpired.

Arteriolar sclerosis as a cause of optic nerve lesions has been recognised by Woods and Rowland (1931), and Draganesco and Lazaresco (1939), and in the two cases (S2 and S3) described below no other cause was found for the optic nerve lesion. That such an association is not very uncommon can be judged by the fact that it occurred in a further four patients referred to the Clinic in 1932 .

\section{Description of Cases mentioned above}

Two cases of optic nerve lesions associated with arteriolar sclerosis.

(Case S3, under the care of Dr. Hickling.)

A housewife, aged 47 years, had been for the past few months increasingly short of breath, when in April, 1931, the sight in her right eye failed quite suddenly. Three weeks later, she presented herself at the Royal Westminster Ophthalmic Hospital for examination. The vision in the right eye was found to be $2 / 60$, and in the left $6 / 12$-there was a right sided papillitis and possibly some blurring of the edges of the left disc. In July she noticed that the sight of the left eye was also going, and on examination she was found to be blind in the right eye and almost so in the left. The right fundus now showed consecutive optic atrophy, and the left papillitis; the vessels of both fundi were very thin, 
with irregular constriction and patches of oedema along their course, and where an artery crossed a vein the latter was distorted. Her heart was enlarged, and her blood pressure was 240/130. Early in 1932 she was admitted to Charing Cross Hospital, and submitted to a very full investigation without any further evidence of disease being found.

Her sight continued to deteriorate, and within two years of the onset she was completely blind.

In 1937 she had to be admitted to another hospital for congestive heart failure, and when last seen in June 1939 she was suffering from chronic congestive heart failure, she was completely blind, her optic discs were china white, with serrated margins, and a few small haemorrhages were seen in the fundi-some of these were over the disc margins.

(Case S3.) A male aged 72 years attended at the Royal Westminster Ophthalmic Hospital in October 1931 under the care of Dr. Adie and Mr. Viner; he reported that during the last year he had become so blind that he could not even see his tea-cup. On examination he had bilateral primary optic atrophy, with considerable arterio-sclerotic changes in the fundus, typified by narrow, thick walled arteries whose lumen in places was almost obliterated by the very great increase in the thickness of the arterial wall. In other places the vessel disappeared entirely under patches of oedema, and kinking of the veins occurred wherever they were crossed by the arteries. His blood pressure, however, was only $170 / 50$, though there was some abnormal thickening and tortuosity of his radial arteries.

His sight varied somewhat from time to time, but since 1937 there has been a very definite, though gradual, improvement. (December 1939 , vision of the right eye $3 / 60$, in the left eye vision not so good. January 1941 , vision in the right eye $6 / 18$ and in the left eye 6/60.)

During the interval he has been seen regularly at approximately monthly intervals, and, apart from his sight, he appears to enjoy excellent health. The condition in the fundi has remained more or less unaltered, and his blood pressure is the same as when first taken.

(Case S2.) A girl aged 19 years, who later developed disseminated sclerosis, though when first seen there were no signs of this condition, apart from retrobulbar neuritis.

This patient consulted Mr. Gimblett at the Royal Westminster Ophthalmic Hospital on September 17, 1931, for progressive loss of vision in the left eye which she had noticed during the last two weeks and which had started with severe, sharp pain in the eyeball. 
The diagnosis of sinusitis was seriously considered in this case, as on direct enquiry it transpired that the first symptoms had occurred during the course of a heavy cold. She was submitted to an extensive and very complete rhinological examination, but no further evidence of disease was found. In the meantime her vision recovered spontaneously, and so it was decided to keep her under observation without adopting any radical form of treatment.

She remained well till January 1933, when she became depressed - she often found herself crying from no apparent cause, and " could not bear the weight of the left leg." A physical examination in March 1933 showed left optic atrophy, intention tremor of the left hand, spasticity and weakness of the left leg, and exaggerated tendon jerks; the plantars were indeterminate.

Again her symptoms underwent a spontaneous remission and she appeared to be healthy, though during a very complete overhaul in June 1939 she stated that she was abnormally prone to laugh or cry, the vision in her left eye was found to be considerably poorer than that of the right, there was temporal pallor of the left disc, well-marked intention tremor of both arms, spastic weakness of both legs, exaggerated tendon jerks, poor abdominal reflexes and bilateral extensor plantar reflexes.

\section{Two cases of papilloedema which underwent spontaneous remission.}

(Case S5.) A housewife aged 37 years consulted Mr. Hine and Dr. Hickling at the Royal Westminster Ophthalmic Hospital on March 2, 1931, for defective vision in the right eye, which she had discovered two weeks previously. On direct enquiry she stated that she had suffered from occipital headaches for the last two or three years, but had never felt sufficiently ill to seek medical advice on this score. On examination, papilloedema and a large central scotoma were found in the right eye; all other investigations proved negative. Within two months the papilloedema subsided, and the vision returned to normal.

She remained perfectly well till the beginning of 1939 , when a radical excision of her breast was performed for carcinoma. Subsequent examination in December 1939 showed no further evidence of disease.

(Case S6). A female aged 29 years was sent by her doctor to the Royal Westminster Ophthalmic Hospital to consult Mr. Viner as to the cause of intermittent severe headaches. These had been present since an attack of influenza one year previously, and were 
often accompanied by vomiting and photophobia. Bilateral papilloedema with one dioptre of swelling was found.

She was admitted to Charing Cross Hospital under the care of Dr. Hickling, where, in spite of an extensive investigation, no further evidence of disease was found-operative interference was decided against, as her vision in both eyes was $6 / 6$ and the fields full. She was kept under careful observation-the headaches ceased after one year, and the papilloedema was observed to be subsiding after four months and was completely gone in the space of two years.

Since first attendance, she was under regular observation at the Royal Westminster Ophthalmic Hospital till December 1939, and during that time she remained perfectly healthy.

\section{$A$ case of sudden failure of vision with bilateral optic atrophy followed by spontaneous recovery.}

(Case S7.) This patient, a printer aged 52 years, consulted Mr. McMullen and Dr. Hickling at the Royal Westminster Ophthalmic Hospital on April 12, 1931, following his discovery at work that he was unable to read. On examination, both optic discs were pale and atrophic, the vision in both eyes was $6 / 60$; the fields were full, and there was no scotoma. Otherwise no evidence of disease could be found, especial attention being directed to evidence of lead poisoning.

He made a rapid recovery, and in three days' time had regained useful vision, though eight months elapsed before he had completely regained his former visual acuity. He remained well, apart from an occasional attack of vertigo, till June 1939, when his visual acuity was recorded as : right $6 / 12$, left $6 / 9$. At this time both discs, though slightly pale, were thought to be within the variation of the normal.

$A$ case of unilateral papilloedema followed by optic atrophy and the development of impotence in an otherwise healthy man.

(Case S8.) A man aged 29 years, the father of two children, first attended the Royal Westminster Ophthalmic Hospital in July, 1928, under the care of Sir Richard Cruise and Dr. Adie, complaining of loss of vision in the right eye occurring during the last four days. He first noticed this condition while suffering from one of a series of headaches to which he had been subject since 1921. On examination, the vision of the right eye was $6 / 24$, there was no field defect, and there was well marked papillitis. He was admitted to Charing Cross Hospital and fully investigated, without any other evidence of disease being found. 
During the subsequent three months the papillitis subsided, though the vision in the right eye continued to deteriorate (in May, 1939 , it was $6 / 60$ ). The appearance of the right disc since 1929 has been that usually described as primary optic atrophy.

Under fairly regular observation he has remained healthy up to the present, except for the poor vision of the right eye, the continuance of the headaches, and the development of impotence since 1928.

\section{Six Cases Diagnosed as Suffering from Disseminated Sclerosis}

Case S15.-Female aged 33 years. Four weeks' history of unilateral retrobulbar neuritis. Found to have intention tremor and exaggerated tendon jerks.

Case S16.-Female aged 42 years. Two weeks' history of right retrobulbar neuritis. Found to have minimal signs of a paraplegia.

Case S17.-Male aged 26 years. Eight or nine years' history of right primary optic atrophy and stress incontinence of urine. Found to have paraplegia, well marked on the left, not so advanced on the right.

Case S18.-Female aged 33 years. Some years' history of right optic atrophy and pain in the right eye. Found to have nystagmus, intention tremor of right arm and spastic paresis of left leg. Little change has occurred between January 28, 1931, and June 1939 in spite of several minor exacerbations and remissions.

Case S19.-Male aged 41 years. Five years' history of bilateral primary optic atrophy. Found to have nystagmus, and exaggerated reflexes in all four limbs.

Case S20.-Female aged 49 years. 'Ten years' history of bilateral primary optic atrophy. Found to have nystagmus, scanning speech, exaggerated tendon jerks and difficulty in starting to micturate.

The five cases diagnosed as tabetic optic atrophy were all men between the ages of forty-three and sixty-four. They all had bilateral primary optic atrophy, the loss of sight was insidious in all save one case, in which this occurred over the period of half an hour. In all these cases Argyll Robertson pupils and absent tendon jerks were demonstrated.

\section{Summary}

Optic nerve lesions usually furnish both subjective and objective evidence of their presence; their detection raises the questions of their ultimate effect on vision, and of other serious disease. 
Although certain appearances of the optic papilla are usually associated with one disease, on occasion other diseases cause similar lesions; for example, a swollen hyperaemic appearance of the disc may occur in hypertension or disseminated sclerosis as well as in papilloedema due to cerebral tumour. Paton (1914) pointed out that swelling of the optic disc in cases of disseminated sclerosis was associated with loss of vision. True papilloedema with no visual loss rarely occurs in cases of hypertension; two such cases are described here.

An isolated lesion occurring in the optic nerve of an otherwise healthy person is regarded by many (Buzzard 1890, Uhthoff 1890, Adie 1930, Benedict 1933, Lillie 1934), as evidence of early disseminated sclerosis. That either abortive cases of disseminated sclerosis cause a fair proportion of optic nerve lesions, or there is some condition analogous to disseminated sclerosis but confined to the optic nerve, is suggested by some cases described by Traquair (1930).

Here described are five cases where an optic nerve lesion appeared in the absence of any obvious cause and where observation for a period of ten years failed to reveal any further pathology. Although these cases have been extensively investigated, no evidence of other disease either in the nervous system or elsewhere has been found to account for the lesions. That such cases are relatively frequent may be judged from the fact that four of them occurred in a consecutive series of twenty-four cases of optic nerve lesion which had been discovered when the patient sought advice for a failure or abnormality of vision. In the same series there were six frank cases of disseminated sclerosis and five of tabetic optic atrophy, while only one doubtful case developed disseminated sclerosis during the period of survey. Unfortunately, eleven patients of this series were lost after periods shorter than one year, and before any cause could be established for the optic nerve lesion.

In conclusion, I would like to thank the honorary staff of Charing Cross Hospital, the National Hospital, Queen Square, and the Royal Westminster Ophthalmic Hospital for permission to record their cases, and especially Dr. R. A. Hickling for his help in preparing this paper.

\section{REFERENCES}

AdIE (1930).-Trans. Ophthal. Soc. U.K., Vol. L, p. 262.

BENEDICT (1933).-Arch. Ophthal. Soc.n.s., Vol. IX, p. 893.

BUz ZARD (1890).- Presidential Address Neurological Society.

Cof FIN (1928).-Ann. of Otol. Rhinol. and Laryngol., Vol. XXXVII, p. 165.

CRANE (1927). -Ann. of Otol. Rhinol. and Laryngol., Vol. XXXVI, p. 201. 
Draganesco and Lazaresco (1939).-Revue d'oto-Neuro-Ophtal., Vol. XVII, p. 107.

GUNn and BUZZARD (1896).-Trans. Ophthal. Soc. U.K., Vol. XVII.

JefFerson (1940).-Proc. Roy. Soc. Med., Vol. XXXIII, p. 685.

LILlie (1934).-Amer. Jl. Ophthal., Vol. XVII, p. 110.

Loe B (1909).-Ann. Otol., Rhinol. and Laryngol., Vol. XVIII, p. 243.

MURPHY and GRILL (1930).-Arch. Internal Med., Vol. XLVI, p. 75.

ONODI (1908). -Ann Otol., Rhinol. and Laryngol., Vol. LXXI, p. 1.

PATON (1914).-Trans. Ophthal. Soc. U.K., Vol. XXXIV, p. 252.

Paton and Holmes (1910).-Brain, Vol. XXXIII, p. 389.

TRAQUaIR (1930).-Trans. Ophthal. Soc. U.K., Vol. L, p. 351.

Uнтн оF (1890).-A rch. fur Psych. und Nervenkrank., Berlin, Vol. 21, p. 55, 303

White (1919).-Ann. Otol., Rhinol. and Laryngol,, Vol. XXVII, p. 793.

- (1924).-Ann. Otol., Rhinol. and Laryngol., Vol. XXXIII, p. 121.

- (1928).-Ann. Otol., Rhinol. and Laryngol., Vol. XXXVII, p. 128.

- (1924).-Laryngoscope, Vol. L, p. 135.

- (1924).-Laryngoscope, Vol. XXXIV, p. 255.

- (1925).-Laryngoscope, Vol. XXXV, p. 217.

Wouds and Rowland (1931).-Jl. Amer. Mea. Ass., XCVII, p. 375.

WALSHE (1940).-Diseases of the Nervous System. Edinburgh, E. and S. Livingstone.

\section{ANNOTATION}

\section{The Education of an Ophthalmic Surgeon}

The paper by Professor Arnold Loewenstein under this heading (p. 45) raises questions of great importance. In this country we have a reputation for being able to muddle through with work of all kinds, and no one can say that the results have been in the long run bad, but it may be a good thing for us to hear what a visitor thinks. Many ophthalmic surgeons in Britain in the past have slipped into their particular niches fortuitously; and not only ophthalmic surgeons, for we remember the story of a young man waiting for an ophthalmic vacancy becoming eventually a distin. guished obstetrician. This was a good many years ago ; but when Brudenell Carter was appointed ophthalmic surgeon at St. George's Hospital in 1870 it was settled that part of his hospital duties was to undertake the responsibility of the obstetrician's holiday work. This was no particular hardship, for as Carter had been in general practice until he was 40 years old he was quite competent to deal with straightforward or difficult cases of labour. Times have changed since then but we feel quite sure that those who have entered specialists' work without any experience of general practice first have missed a great deal. The converse, when an elderly general practitioner gives up general practice for ophthalmology, is not at all common; but has occurred in a few instances. So long as these 